\title{
Heterogeneity of Circulating Tumor Cells in Neoadjuvant Chemotherapy of Breast Cancer
}

\author{
Evgeniya V. Kaigorodova ${ }^{1,2, *(\mathbb{C})}$, Olga E. Savelieva ${ }^{1,3}{ }^{(1)}$, Liubov A. Tashireva ${ }^{1}$ (D), \\ Natalia A. Tarabanovskaya ${ }^{1}$, Elena I. Simolina ${ }^{1}$, Evgeny V. Denisov ${ }^{1,3}$ (iD), \\ Elena M. Slonimskaya ${ }^{1,2}$, Evgeny L. Choynzonov ${ }^{1,2}$ and Vladimir M. Perelmuter ${ }^{1}$ \\ 1 Cancer Research Institute, Tomsk National Research Medical Center, Tomsk 634050, Russia; \\ olga_chechina@mail.ru (O.E.S.); lkleptsova@mail.ru (L.A.T.); tarabanovskaya@inbox.ru (N.A.T.); \\ simolin12@sibmail.com (E.I.S.); d_evgeniy@oncology.tomsk.ru (E.V.D.); slonimskaya@yandex.ru (E.M.S.); \\ nii@oncology.tomsk.ru (E.L.C.); pvm@ngs.ru (V.M.P.) \\ 2 Siberian State Medical University, Tomsk 634050, Russia \\ 3 Laboratory for Translational Cellular and Molecular Biomedicine, Tomsk State University, \\ Tomsk 634050, Russia \\ * Correspondence: zlobinae@mail.ru or kaigorodova@oncology.tomsk.ru; Tel.: +7-(3822)-28-26-86 \\ Academic Editors: Samuel Achilefu and Derek J. McPhee \\ Received: 16 January 2018; Accepted: 18 March 2018; Published: 22 March 2018

\begin{abstract}
The biological properties of circulating tumor cells (CTCs), and their dynamics during neoadjuvant chemotherapy are important, both for disease progression prediction and therapeutic target determination, with the aim of preventing disease progression. The aim of our study was to estimate of different CTC subsets in breast cancer during the NACT (neoadjuvant chemotherapy). The prospective study includes 27 patients with invasive breast cancer, T2-4N0-3M0, aged 32 to 60 years. Venous heparinized blood samples, taken before and after biopsy, after each courses of chemotherapy (on days 3-7), and before surgical intervention, served as the material for this study. Different subsets of circulating tumor cells were determined on the basis of the expression of EpCAM, CD45, CD44, CD24, and N-Cadherin using flow cytometry. As the result of this study, it has been observed that significant changes in the quantity of the different subsets of circulating tumor cells in patients' blood were observed after carrying out the 3rd course of NACT. NACT causes significant changes in the quantity of six CTC subsets, with various combinations of stemness and epithelial-mesenchymal transition (EMT) properties.
\end{abstract}

Keywords: heterogeneity of circulating tumor cells; EMT; EpCAM-negative circulating tumor cells; NACT; breast cancer

\section{Introduction}

Apparently, the presence of CTCs (circulating tumor cells) is not always followed by metastases, as not all tumor cells appearing in the bloodstream have the necessary properties. CTCs are a heterogeneous population. Some cells are cancer stem cells, other cells are in an EMT (epithelial-mesenchymal transition) state, and most of the cells do not have EMT and stemness properties [1-3]. A meta-analysis of 24 studies (3701 patients), including 13 prospective and 11 retrospective studies devoted to the determination of prognostic importance of CTC detection on patients with breast cancer, shows that a large number of CTCs is associated with poor treatment response, shortening of the overall and disease-free survival rates [4]. It was shown that neoadjuvant chemotherapy (NACT) on breast cancer does not act on CTCs in the EMT state [5]. Nevertheless, existing studies do not have complete information about which CTC subsets are associated with haematogenous metastases and poor outcome, and how different types of CTCs react to NACT. 
Therefore, the aim of our study is to estimate different CTC subsets in breast cancer during the NACT.

\section{Results and Discussion}

On the basis of the determination of the membrane expression of EpCAM, CD44, CD24, CD45, and N-Cadherin, in our study, we determined six subsets of CTCs: CTC-1-circulating tumor cells without stemness and EMT properties (EpCAM+CD45-CD44-CD24-Ncadherin-); CTC-2 - circulating tumor cells without stemness and with EMT properties (EpCAM+CD45-CD44-CD24-Ncadherin+); CTC-3-circulating tumor stem cells without EMT properties (EpCAM+CD45-CD44+CD24-Ncadherin-); CTC-4 — circulating tumor stem cells with EMT properties (EpCAM+CD45-CD44+CD24-Ncadherin+); CTC-5-circulating tumor stem cells with an absence of EpCAM membrane expression and without EMT properties (EpCAM-CD45-CD44+CD24-Ncadherin-); and CTC-6-circulating tumor stem cells with an absence of EpCAM membrane expression and with EMT properties (EpCAM-CD45-CD44+CD24-Ncadherin+).

Breast cancer patients show significant variability in terms of the quantity of the studied CTC subsets in peripheral blood before diagnostic and treatment procedures. Thus, CTC-3 was detected in minimal concentrations $-0.00(0.00-0.43)$ cells per $\mu \mathrm{L}$. In comparison, the concentrations of CTC- 1 and CTC-5 are significantly higher (respectively, $0.546(0.00-1.11)$ cells per $\mu \mathrm{L}(p=0.001)$ and $0.18(0.00-2.42)$ cells per $\mu \mathrm{L}(p=0.011)$ ) (Table 1$)$. All CTC subsets were absent in the peripheral blood of healthy donors $(0.00(0.00-0.00)$ cells per $\mu \mathrm{L})$.

Table 1. Different populations of circulating tumor cells (CTCs) in the blood of breast cancer patients before biopsy, Me (Q1-Q3), cells per $\mu \mathrm{L}$.

\begin{tabular}{|c|c|c|c|c|c|c|c|}
\hline $\mathbf{N}$ & CTC Total & CTC-1 & CTC-2 & CTC-3 & СТC-4 & CTC-5 & CTC-6 \\
\hline & 1 & 2 & 3 & 4 & 5 & 6 & 7 \\
\hline \multicolumn{8}{|c|}{ Breast cancer patients } \\
\hline 27 & $\begin{array}{c}2.85 \\
(0.51-4.40)\end{array}$ & $\begin{array}{c}0.54 \\
(0.00-1.11) \\
p_{2-1}=0.00003\end{array}$ * & $\begin{array}{c}0.09 \\
(0.00-0.70) \\
p_{3-1}=0.00009 * \\
p_{3-2}=0.47^{*}\end{array}$ & $\begin{array}{c}0.00 \\
(0.00-0.43) \\
p_{4-1}=0.00002 * \\
p_{4-2}=0.00111^{*} \\
p_{4-3}=0.11 \text { * }\end{array}$ & $\begin{array}{c}0.02 \\
(0.00-0.63) \\
p_{5-1}=0.00009 * \\
p_{5-2}=0.33^{*} \\
p_{5-3}=0.43^{*} \\
p_{5-4}=0.68^{*}\end{array}$ & $\begin{array}{c}0.18 \\
(0.00-2.41) \\
p_{6-1}=0.00003^{*} \\
p_{6-2}=0.14^{*} \\
p_{6-3}=0.67 * \\
p_{6-4}=0.011^{*} \\
p_{6-5}=0.23^{*}\end{array}$ & $\begin{array}{c}0.04 \\
(0.00-0.34) \\
p_{7-1}=0.00006^{*} \\
p_{7-2}=0.57^{*} \\
p_{7-3}=0.47^{*} \\
p_{7-4}=0.79^{*} \\
p_{7-5}=0.58^{*} \\
p_{7-6}=0.19^{*}\end{array}$ \\
\hline \multicolumn{8}{|c|}{ Healthy donors } \\
\hline 7 & $\begin{array}{c}0.00 \\
(0.00-0.00)\end{array}$ & $\begin{array}{c}0.00 \\
(0.00-0.00)\end{array}$ & $\begin{array}{c}0.00 \\
(0.00-0.00)\end{array}$ & $\begin{array}{c}0.00 \\
(0.00-0.00)\end{array}$ & $\begin{array}{c}0.00 \\
(0.00-0.00)\end{array}$ & $\begin{array}{c}0.00 \\
(0.00-0.00)\end{array}$ & $\begin{array}{c}0.00 \\
(0.00-0.00)\end{array}$ \\
\hline
\end{tabular}

In a previously published study, we showed that, after biopsy of invasive breast cancer, the quantity of CTC-1 without stemness and EMT properties (EpCAM+CD45-CD44-CD24-Ncadherin-) and CTC-3 with stemness and without EMT properties (EpCAM+CD45-CD44+CD24-Ncadherin-) were increased [6].

Neoadjuvant chemotherapy was carried out after biopsy, which, itself, affects CTC quantity. Therefore, the quantity of each CTC subsets after a regular chemotherapy course was compared with the quantity of respective CTC subsets after biopsy. As the result of this prospective study, the most significant changes in the levels of different CTC subsets were observed during the first three courses of NACT. The total number of CTCs tended to increase after the 3rd course of NACT and significantly increased before the surgery regardless of the presence or absence of stem or EMT features. Various CTC subsets reacted to NACT differently. The only CTC subset with no changes after NACT was CTC-2 (cancer cells without stemness and with EMT properties) (Table 2). 
Table 2. Effect of neoadjuvant chemotherapy on the level of different populations of CTCs in the blood of breast cancer patients Me (Q1-Q3), cells per $\mu \mathrm{L}$.

\begin{tabular}{|c|c|c|c|c|}
\hline Level after Biopsy & $\begin{array}{c}\text { Level after } 1 \\
\text { Course of NACT }\end{array}$ & $\begin{array}{c}\text { Level after } 2 \\
\text { Course of NACT }\end{array}$ & $\begin{array}{l}\text { Level after } 3 \\
\text { Course of NACT }\end{array}$ & $\begin{array}{l}\text { Level before Surgical } \\
\text { Treatment }\end{array}$ \\
\hline 1 & 2 & 3 & 4 & 5 \\
\hline \multicolumn{5}{|c|}{ CTC total (EpCam+/-CD45-CD44+/-CD24-Ncadherin+/-) } \\
\hline $2.97(0.93-5.85)$ & $\begin{array}{l}2.51(1.85-21.45) \\
\quad p_{2-1}=0.32\end{array}$ & $\begin{array}{c}11.04(3.46-21.96) \\
p_{3-1}=0.77 \\
p_{3-2}=0.20\end{array}$ & $\begin{array}{c}19.94(9.28-130.86) \\
p_{4-1}=0.068 \\
p_{4-2}=0.26 \\
p_{4-3}=0.32\end{array}$ & $\begin{array}{c}14.06(4.51-74.60) \\
p_{5-1}=0.017 \\
p_{5-2}=0.035 \\
p_{5-3}=0.16 \\
p_{5-4}=0.77\end{array}$ \\
\hline \multicolumn{5}{|c|}{ CTC-1 without stemness and EMT properties (EpCam+CD45-CD44-CD24-Ncadherin-) } \\
\hline $0.90(0.00-1.73)$ & $\begin{array}{l}1.25(0.07-5.21) \\
p_{2-1}=0.074\end{array}$ & $\begin{array}{c}3.75(0.29-5.79) \\
p_{3-1}=0.027 \\
p_{3-2}=0.916\end{array}$ & $\begin{array}{c}0.74(0.31-4.80) \\
p_{4-1}=0.176 \\
p_{4-2}=0.735 \\
p_{4-3}=0.735\end{array}$ & $\begin{array}{c}3.45(0.00-7.09) \\
p_{5-1}=0.028 \\
p_{5-2}=0.600 \\
p_{5-3}=0.310 \\
p_{5-4}=0.310\end{array}$ \\
\hline \multicolumn{5}{|c|}{ CTC-2 without stemness and with EMT properties (EpCam+CD45-CD44-CD24-Ncadherin+) } \\
\hline $1.03(0.45-22.50)$ & $\begin{array}{l}0.28(0.17-0.66) \\
p_{2-1}=0.345\end{array}$ & $\begin{array}{c}0.87(0.39-5.99) \\
p_{3-1}=0.916 \\
p_{3-2}=0.345\end{array}$ & $\begin{array}{c}0.83(0.29-1.84) \\
p_{4-1}=0.463 \\
p_{4-2}=0.735 \\
p_{4-3}=0.600\end{array}$ & $\begin{array}{c}0.28(0.00-1.28) \\
p_{5-1}=0.865 \\
p_{5-2}=0.046 \\
p_{5-3}=0.753 \\
p_{5-4}=0.753\end{array}$ \\
\hline \multicolumn{5}{|c|}{ CTC-3 with stemness and without EMT properties (EpCam+CD45-CD44+CD24-Ncadherin-) } \\
\hline $0.02(0.00-0.22)$ & $\begin{array}{l}0.12(0.00-1.09) \\
p_{2-1}=0.310\end{array}$ & $\begin{array}{c}0.20(0.00-1.63) \\
p_{3-1}=0.176 \\
p_{3-2}=0.079\end{array}$ & $\begin{array}{c}0.50(0.00-1.79) \\
p_{4-1}=0.115 \\
p_{4-2}=0.115 \\
p_{4-3}=0.916\end{array}$ & $\begin{array}{c}0.00(0.00-2.57) \\
p_{5-1}=0.498 \\
p_{5-2}=0.224 \\
p_{5-3}=0.892 \\
p_{5-4}=0.753\end{array}$ \\
\hline \multicolumn{5}{|c|}{ CTC-4 with stemness and EMT properties (EpCam+CD45-CD44+CD24-Ncadherin+) } \\
\hline $0.22(0.00-0.55)$ & $\begin{array}{l}0.00(0.00-0.26) \\
p_{2-1}=0.715\end{array}$ & $\begin{array}{c}0.05(0.00-0.22) \\
p_{3-1}=0.345 \\
p_{3-2}=0.500\end{array}$ & $\begin{array}{c}0.00(0.00-1.64) \\
p_{4-1}=0.144 \\
p_{4-2}=0.108 \\
p_{4-3}=0.224\end{array}$ & $\begin{array}{c}0.01(0.00-0.71) \\
p_{5-1}=0.043 \\
p_{5-2}=0.043 \\
p_{5-3}=0.115 \\
p_{5-4}=0.892\end{array}$ \\
\hline \multicolumn{5}{|c|}{$\begin{array}{l}\text { CTC-5 with stemness, without EMT properties and without EpCAM membrane expression } \\
\text { (EpCam-CD45-CD44+CD24-Ncadherin-) }\end{array}$} \\
\hline $0.00(0.00-0.49)$ & $\begin{array}{l}0.46(0.00-2.61) \\
p_{2-1}=0.892\end{array}$ & $\begin{array}{c}1.08(0.13-5.32) \\
p_{3-1}=0.310 \\
p_{3-2}=0.310\end{array}$ & $\begin{array}{c}5.62(2.12-9.57) \\
p_{4-1}=0.068 \\
p_{4-2}=0.123 \\
p_{4-3}=0.025\end{array}$ & $\begin{array}{c}2.39(0.10-12.80) \\
p_{5-1}=0.086 \\
p_{5-2}=0.498 \\
p_{5-3}=0.128 \\
p_{5-4}=0.207\end{array}$ \\
\hline \multicolumn{5}{|c|}{$\begin{array}{l}\text { CTC-6 with stemness and EMT properties and without EpCAM membrane expression } \\
\text { (EpCam-CD45-CD44+CD24-Ncadherin+) }\end{array}$} \\
\hline $0.16(0.04-1.59)$ & $\begin{array}{l}0.32(0.06-0.87) \\
p_{2-1}=1.00\end{array}$ & $\begin{array}{c}0.21(0.02-2.35) \\
p_{3-1}=0.498 \\
p_{3-2}=0.865\end{array}$ & $\begin{array}{c}2.95(1.25-13.28) \\
p_{4-1}=0.027 \\
p_{4-2}=0.062 \\
p_{4-3}=0.310\end{array}$ & $\begin{array}{c}3.19(0.47-9.41) \\
p_{5-1}=0.027 \\
p_{5-2}=0.090 \\
p_{5-3}=0.345 \\
p_{5-4}=0.779\end{array}$ \\
\hline
\end{tabular}

Wilcoxon Matched Pairs Test. Marked tests are significant at $p<0.05000$.

Despite the fact that initial quantity of CTCs without stemness and EMT properties (CTC-1) was large and increased after biopsy, the number of these cells grew after NACT. The tendency of growth appeared after the first course $(p=0.07)$, while significant growth of that cell's quantity was registered after the second course $(p=0.027)$, as well as after the end of NACT and before surgical treatment 
$(p=0.046)$ compared with the level of these cells in patient blood after biopsy. It should be noted that the presence of stemness properties in four CTC subsets does not guarantee an equal response to NACT. The quantity of stem EpCAM+ CTC-3 and EpCAM- CTC-5 without EMT properties after the third course of NACT increased on the level of a trend ( $p=0.101$ and $p=0.068$, respectively). The quantity of stem CTC-4 cells with membrane expression of EpCAM and EMT properties decreased, and the level of these cells in blood after NACT (before surgical treatment) was significantly lower compared with the same characteristics after biopsy, and equaled $0.01(0.00-0.71)$ cells per $\mu \mathrm{L}$ and $0.219(0.00-0.55)$ cells per $\mu \mathrm{L}$, respectively $(\mathrm{Z}=2.02, p=0.043)$.

Unlike other stem CTC subsets, after three courses of NACT, a heavy increase in the quantity of CTC-6 (with an absence of EpCAM membrane expression and with EMT properties) to 2.95 (1.25-13.28) cells per $\mu \mathrm{L}$, compared with the level of these cells in blood after biopsy $(0.16(0.04-1.59)$ cells per $\mu \mathrm{L}$, $\mathrm{Z}=2.19, p=0.027$ ) was observed in patient blood.

The results of the study showed that NACT has a significant impact on CTC quantity. It is possible to say that CTC subsets are sensitive to NACT, to a greater or lesser degree. Studied CTC subsets were characterized using various combination of EpCAM membrane expression, stem markers (CD44+CD24-), and EMT markers (N-Cadherin+). It seems that the ability of tumor cells to express or not express the mentioned molecules does not play a fundamental role in their capacity to intravasate. CTC levels changes by many mechanisms: Cells' ability to intravasate, loss of epithelial markers (such as EpCAM and cytokeratines), extravasation, and the intravascular death of tumor cells. Considering that the half-life of CTCs is very short, and is equal to 1-2.5 h [7], determination of the formation mechanisms of CTCs with different phenotypes will always be a cause of difficulties.

EpCAM is a main epithelial antigen for CTCs isolation and characterization. Thus, CTCs with a loss of EpCAM membrane expression can't be detected [8-10]. Therefore, cells with an absence of EpCAM membrane expression are beyond the interest of scientists. EpCAM (Epithelial cell adhesion molecule) is a molecule of cell adhesion and a transmembrane glycoprotein expressing only on the epithelium [11]. EpCAM is involved, not only in cell adhesion, but also in signaling [12-14], proliferation, differentiation and migration $[15,16]$. Numerous immunohystochemical studies have shown that EpCAM overexpresses in the cells of breast, prostatic, ovarian, lungs, colon, renal and gastric carcinoma [17-19]. A decrease of EpCAM expression is associated with epithelial-mesenchymal transition. In addition, there is some evidence concerning the reduction of EpCAM expression in CTCs [20].

For verification of the hypothesis, that loss of EpCAM membrane expression in stem CTCs (EpCAM-negative CTCs) is caused by EpCAM translocation into a cell and not by its true absence, we isolated CTC-5 (EpCAM-CD45-CD44+CD24-Ncadherin-) and CTC-6 (EpCAM-CD45-CD44+CD24-Ncadherin+) from blood using the cell-sorting technique. Further, using anti-EpCAM and anti-CK7 antibodies, we estimated the characteristics of intracellular EpCAM expression using confocal microscopy. Based on the results of this research, it was shown that, in the N-Cadherin-negative subset of stem cells CTC-5 (without EMT properties), both cytoplasmic and nuclear granular expression of EpCAM, combined with CK7 expression, were observed (Figure 1a). In N-Cadherin-positive stem cells CTC-6 (with EMT properties), only cytoplasmic diffuse expression of EpCAM was observed. Moreover, the expression of CK7 was absent (Figure 1b). It could be that the obtained results demonstrate the available information regarding the fact that EpCAM translocating into nuclei initiates EMT [21].

We suggest that localization of EpCAM expression in the CTC- 5 and CTC-6 subsets show consecutive phases of the same process. In CTC-5, EpCAM is translocated into the cytoplasm and nuclei, where it may further initiate EMT. Furthermore, expression of CK7 (epithelial marker) remains while expression of N-Cadherin (mesenchymal marker) is absent. It seems that, in CTC-6, induction of EMT already occurred. There was no EpCAM expression in nuclei, CK7 expression was lost, but expression of $\mathrm{N}$-Cadherin was still observed. It should be noted that rare cells with nuclear EpCAM expression were detected among CTC-5 and rare CK7-negative cells were detected among CTC-6. Apparently, the induction of EMT in stem CTCs by EpCAM translocation is not the only mechanism. In stem CTC-4, N-Cadherin expression is combined with EpCAM membrane expression. 
Tumor cells in EMT are able to survive under genotoxic and other influences and are generally resistant to chemotherapy and radiotherapy [22]. It is known that cancer stem cells are also resistant to chemotherapy [23].

Stem and EMT properties are often combined. It was shown that, in RAS or HER2 overexpressing tumor cells, the subset with stem properties CD44+CD24- increased the potential of EMT [24,25]. Among breast cancer cells with the phenotype CD44+CD24-/low, there is a subtype with a "claudin-low" phenotype, which is thought to express many of the EMT-associated genes, such as FoxC2, Zeb, and N-Cadherin [26,27]. It is important to note that EMT inductors may cause the appearance of stem properties in cells [28,29]. The importance of EMT in the manifestation of different stages of metastases is well-acknowledged [30].

(a)
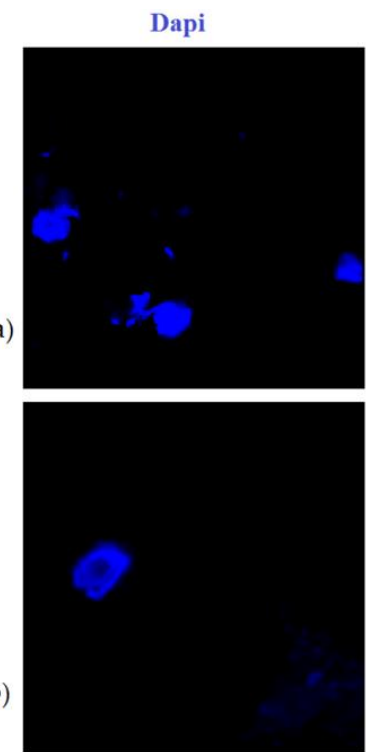

Epcam
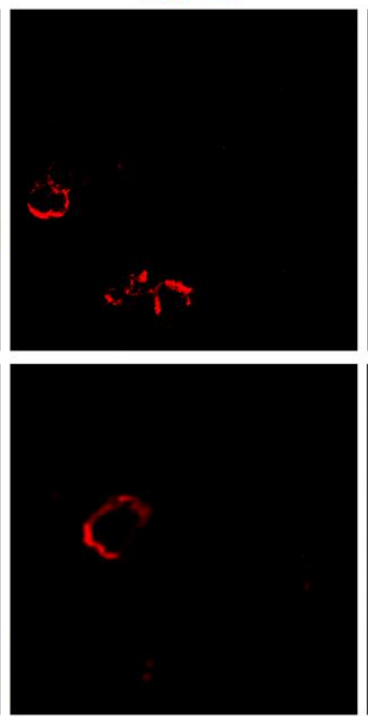

Cytokeratine 7
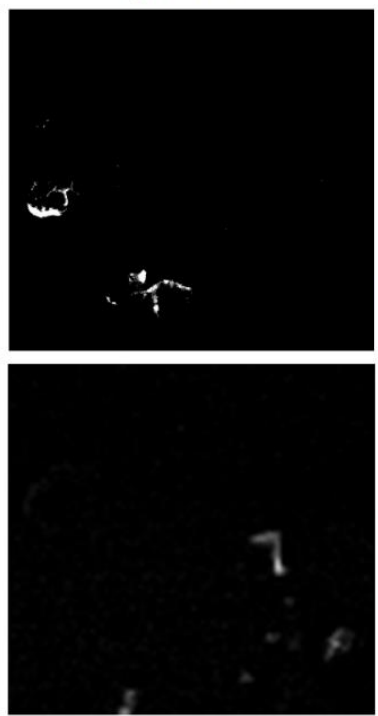

Merge
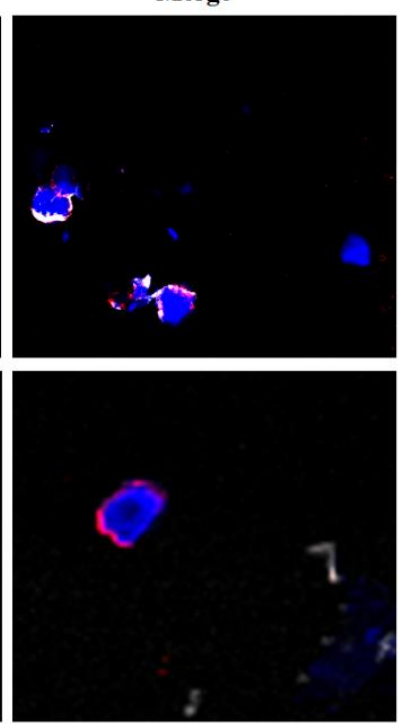

Figure 1. Characteristics of EpCAM-negative CTCs: (a) CTC-5 subset isolated from blood by EpCAM-CD45-CD44+CD24-Ncadherin- phenotype using the cell sorter MoFlo XDP (Beckman Coulter, Franklin Lakes, FL, USA). Lumpy EpCAM expression is observed in cytoplasm and in nuclei of tumor cells, CK7 is expressed in cytoplasm (confocal microscopy, $\times 630$ ); (b) CTC-5 subset isolated from blood by EpCAM-CD45-CD44+CD24-Ncadherin+ phenotype using the cell sorter MoFlo XDP (Beckman Coulter, Franklin Lakes, FL, USA). Diffuse EpCAM expression is observed in cytoplasm of tumor cells, CK7 expression is absent (confocal microscopy, $\times 630$ ).

\section{Materials and Methods}

\subsection{Research Materials}

The prospective study includes 27 patients with invasive breast cancer T2-4N0-3M0 aged 32 to 60 years admitted for treatment in Cancer Research Institute, Tomsk National Research Medical Center. Neoadjuvant chemotherapy was carried out for 14 patients. 13 patients were in the group without NACT. Venous heparinized blood samples taken before and after biopsy, after each courses of chemotherapy on 3-7 day, and before surgical intervention have served as a material for the study. Venous blood samples $(5 \mathrm{~mL})$ were collected in tubes containing heparin and used in the analysis during $2 \mathrm{~h}$. The study was approved by the Local Committee for Medical Ethics of our Institute, and informed consents were obtained from all patients prior to analysis. The clinicopathological parameters of the patients with breast cancer are presented in Table 3. Seven healthy volunteers were included in the control group. 
Table 3. The clinicopathological parameters of the patients with breast cancer.

\begin{tabular}{|c|c|}
\hline Clinicopathological Parameters & $\mathbf{N}(\%)$ \\
\hline \multicolumn{2}{|c|}{ Age (year) (Me (Q1-Q3)) } \\
\hline $49(43-57)$ & $27(100 \%)$ \\
\hline \multicolumn{2}{|c|}{ Molecular type of breast cancer } \\
\hline Luminal A & $6 / 27(22 \%)$ \\
\hline Luminal B1 & $12 / 27(44 \%)$ \\
\hline Luminal B2 & $1 / 27(4 \%)$ \\
\hline HER2-positive & $1 / 27(4 \%)$ \\
\hline Triple-negative & $7 / 27(26 \%)$ \\
\hline \multicolumn{2}{|l|}{ Tumor size } \\
\hline $\mathrm{T} 1$ & $6 / 27(22 \%)$ \\
\hline $\mathrm{T} 2$ & $18 / 27(67 \%)$ \\
\hline T3 & $1 / 27(4 \%)$ \\
\hline $\mathrm{T} 4$ & $2 / 27(7 \%)$ \\
\hline \multicolumn{2}{|c|}{ Lymph node status } \\
\hline No & $14 / 27(52 \%)$ \\
\hline N1 & $8 / 27(30 \%)$ \\
\hline N2 & $3 / 27(11 \%)$ \\
\hline N3 & $2 / 27(7 \%)$ \\
\hline \multicolumn{2}{|c|}{ Neoadjuvant chemotherapy (NACT) } \\
\hline $\mathrm{NO}$ & $13 / 27(48 \%)$ \\
\hline YES & $14 / 27(52 \%)$ \\
\hline
\end{tabular}

\subsection{Flow Cytometry}

Different populations of CTCs were evaluated by flow cytometry using a BD FACSCanto II system (Becton, Dickinson and Company (BD), Franklin Lakes, FL, USA) with BD FACS Diva software. For this procedure, stabilized heparin venous blood was incubated with fluorochrome-labeled monoclonal antibodies to CD45 (clone F10-89-4, PE/Cy7) (Abcam, Cambridge, UK), CD44 (clone IM7, FITC) (Abcam, Cambridge, UK), CD24 (clone SN3, PE) (Abcam, Cambridge, UK), EpCAM (clone VU-1D9, PerCP/Cy5.5) (Abcam, Cambridge, UK) and CD325 (N-Cadherin) (clone 8C11, APC) (Biolegend, San Diego, CA, USA). Then, erythrocytes were lysed in lysis solution (BD FACS lysing solution) and washed twice with Cell Wash buffer. The cell pellet was resuspended in $1 \mathrm{~mL}$ of BD Flow buffer. All samples were stored in the dark at $4{ }^{\circ} \mathrm{C}$ and were analyzed within $1 \mathrm{~h}$. Measurement was done against unstained control.

The following molecular markers for CTCs were analyzed: EpCAM, CD45, CD44, CD24 and CD325 (N-cadherin). The cells were then classified based on the evidence of the EMT and the presence or absence of stem cell markers: CTC-1 (EpCAM+CD45-CD44-CD24-Ncadherin-); CTC-2 (EpCAM+CD45-CD44-CD24-Ncadherin+); CTC-3 (EpCAM+CD45-CD44+CD24-Ncadherin-); CTC-4(EpCAM+CD45-CD44+CD24-Ncadherin+); CTC-5(EpCAM-CD45-CD44+CD24-Ncadherin-); CTC-6 (EpCAM-CD45-CD44+CD24-Ncadherin+).

The results are reported as the proportion of the number of events with respect to CD45 expression multiplied by the concentration of leucocytes in $1 \mu \mathrm{L}$ of blood. To perform this analysis simultaneously with immunophenotyping, cells were placed in a hematology analyzerLH500 to determine the total number of blood leukocytes. The level of CTCs in the sample was expressed as the number of cells per $\mu \mathrm{L}$ of blood and was determined by the formula:

CTC, cells per $\mu \mathrm{L}=\left(\frac{\text { Events of the CTC population }}{\text { Events of CD45+ }}\right) \times$ Leukocyte concentration, cells per $\mu \mathrm{L}$ 


\subsection{Fluorescence-Activated Cell Sorting}

Stem EpCAM-negative CTCs (CTC-5 (EpCAM-CD45-CD44+CD24-Ncadh-) and CTC-6 (EpCAM-CD45-CD44+CD24-Ncadh+) subpopulations) were sorted using a cell sorter MoFlo XDP with Summit software (Beckman Coulter, USA). For this procedure, stabilized heparin venous blood was incubated with fluorochrome-labeled monoclonal antibodies to CD45 (PE/Cy7, mouse IgG1, clone HI30, BD Pharmingen, San Diego, CA, USA), CD44 (APC-H7, mouse IgG2b, clone G44-26, BD Pharmingen, USA), CD24 (PerCP-Cy5.5, mouse IgG2a, clone ML5, BD Pharmingen, USA), EpCAM (FITC, mouse IgG1, clone EBA-1, BD Pharmingen, USA) and CD325 (N-Cadherin) (PE, mouse IgG1, clone 8C11, BD Pharmingen, USA). Isotype control antibodies (mouse PE-Cy7 IgG1, mouse APC-H7 IgG2b, mouse PerCP-Cy5.5 IgG2a, mouse PE IgG1, BD Pharmingen, USA) were used for negative control. Then erythrocytes were lysed in $1 \mathrm{~mL}$ VersaLyse Lysing Solution (Beckman Coulter, USA). Side scatter and forward scatter profiles were used to eliminate cell doublets. Then EpCAM-CD45-CD44+CD24-Ncadhand EpCAM-CD45-CD44+CD24-Ncadh+ cells were routinely sorted.

\subsection{CTCs Spiking Experiment}

Blood specimens ( $5 \mathrm{~mL}$ vacuum tubes with heparin) for three spiking experiments were drawn under informed consent from healthy donors and breast cancer patients at Cancer Research Institute, Tomsk National Research Medical Center according to a protocol approved by the Local Committee for Medical Ethics. Whole blood $(100 \mu \mathrm{L})$ of healthy donor was spiked with the known number (range 18-33 CTCs) of CTCs which were isolated using a cell sorter MoFlo XDP with Summit software. Three samples of the enriched blood were counted on a flow cytometer. The results of the flow cytometry assay ranged from $89 \%$ to $103 \%$ (CV 6\%).

\subsection{Confocal Microscopy}

Visualization of isolated subsets of stem EpCAM-negative CTCs was carried out on confocal microscope LSM 780 NLO (Carl Zeiss, On Cohen, Germany). In order to do that cell suspension after sorting was dried on glass with poly-L-lysin coating, fixated with cold methanol and incubated with $3 \%$ BSA in $1 \times$ PBS with $0.02 \%$ Tween 20 (Amresco, Dallas, TX, USA) during 45 min for preventing non-specific antibody binding. Further the primary antibodies rabbit anti-EpCAM (polyclonal, 1:2000, Abcam, Cambridge, UK) and goatanti-CK7 (polyclonal, 1:50, Santa Cruz Biotechnology, Dallas, TX, USA) in 1\% BSA were added and incubated in dark during $30 \mathrm{~min}$. Then were washed with PBS and after that the cocktail of second conjugated antibodies Anti-Rabbit IgG H\&L (Cy3) (Abcam, Cambridge, UK) and Anti-Goat IgG H\&L (AlexaFluor 647) (Abcam, Cambridge, UK) was added. Sections were covered by Mounting Medium with DAPI (Dako, Carpinteria, CA, USA) and analyzed with the laser scanning microscope LSM 780 NLO (Carl Zeiss, Oberkochen, Germany) with magnification $\times 630$.

\subsection{Statistical Analysis}

All the statistical analyses were performed by using the Statistica 10.0. (data analysis software system) (StatSoft, Inc., Tulsa, OK, USA). The obtained data were processed using variation statistics. Assessment of the normal distribution of the results was performed using the Kolmogorov-Smirnov test. The significance of differences was assessed using the nonparametric Mann-Whitney test (for independent samples) and the Wilcoxon $(\mathrm{Z})$ test (for dependent samples). Data are presented as the median $(\mathrm{Me})$ and the upper and lower quartiles (Q1-Q3). Two-sided $p$-values of $<0.05$ were considered statistically significant.

\section{Conclusions}

Both EMT and stemness may be described by several markers. Thus, our data is true for cells with EMT and/or stemness markers used in this manuscript. Among the six studied CTC subsets, there were cells with stemness and EMT properties, with a combination of these properties, and also 
without any of them. CTC subsets analyzed in our study reflect both relatively stable cell phenotypes (e.g., cells without stemness and EMT and cells with stemness but without EMT features) and transient states which are peculiar to EMT. It can be stem cells that undergo EMT and display both the presence and absence of membrane expression of EpCAM as well as cytoplasmic/nuclear expression of EpCAM. In addition, non-stem cells in an EMT state with membrane expression of EpCAM and its loss can be also considered as transient cell states. Transient EMT phenotypes which are thought to be able to remain in fixed state for an indefinite time play a key role in invasion and metastasis as well as in chemotherapy resistance [31,32]. Epithelial-mesenchymal plasticity is believed to be maintained by several EMT programs. Moreover, the activation of EMT is probably a main mechanism of stem cell generation both from normal and carcinoma cells [31,33,34]. However, it is still unclear how EMT program is related to acquiring of stemness features [32]. Moreover, it is believed that EMT and stemness may occur independently from each other [35].

The quantity of tumor cells in peripheral blood resulted from three processes: Recruiting and intravasation in the tumor, destruction in remote organs, and extravasation in certain organs. In a heterogeneous population of CTCs, there are subsets of cells in which the quantity changed under the influence of NACT, as well as subsets of cells with no changes in terms of quantity. Increase of CTC-1 and CTC- 6 quantity and a reduction of CTC-4 quantity after NACT do not eliminate its potential contribution in haematogenous metastases. The increase of CTCs might be evidence of preponderance of intravasation over intravascular death or extravasation, while the reduce of CTCs might be indicator of predominance extravasation over intravasation. It should be taken into account that, for haeamatogenous metastases development, the most important property of "cells-seeds" is the ability to effectively interact with cell elements and molecules of premetastatic niches [36,37].

It is reasonable to give special consideration to CTCs with a loss of EpCAM membrane expression and their intracellular translocation (CTC-5 and CTC-6). CTC subsets that are more likely responsible for metastases development are to be studied in further research. During NACT, it is necessary to consider the significant impact on heterogeneity of CTCs, which may increase the risk of haematogenous metastases.

Acknowledgments: Authors gratefully acknowledge the financial support from Russian Scientific Foundation (Grant No 16-15-10221).

Author Contributions: Vladimir M. Perelmuter, Evgeniya V. Kaigorodova, Olga E. Savelieva, Liubov A. Tashireva conceived and designed the experiments; Evgeniya V. Kaigorodova, Olga E. Savelieva, Liubov A. Tashireva performed the experiments and did the data analyses; Natalia A. Tarabanovskaya, Elena I. Simolina, Elena M. Slonimskaya, Evgeny L. Choynzonov performed the diagnosis, monitoring and treatment of breast cancer patients; Evgeniya V. Kaigorodova, Vladimir M. Perelmuter and Evgeny V. Denisov wrote the paper. All authors read and approved the final version of the manuscript.

Conflicts of Interest: The authors declare no conflict of interest.

\section{References}

1. Giordano, A.; Gao, H.; Anfossi, S.; Cohen, E.; Mego, M.; Lee, B.N.; Tin, S.; De Laurentiis, M.; Parker, C.A.; Alvarez, R.H.; et al. Epithelial-mesenchymal transition and stem cell markers in patients with HER2-positive metastatic breast cancer. Mol. Cancer Ther. 2012, 11, 2526-2534. [CrossRef] [PubMed]

2. Kaigorodova, E.; Tarabanovskaya, N.; Simolina, E.; Perelmuter, V.; Stakheeva, M.; Cherdyntseva, N.; Saveleva, O.; Tashireva, L. Circulating tumor cells and bone marrow progenitor cells in the blood of breast cancer patients in the dynamics of neoadjuvant chemotherapy. EJC Suppl. 2015, 13, 22. [CrossRef]

3. Kaigorodova, E.V. Circulating tumor cells: Clinical significance in breast cancer (Review). Ann. Russ. Acad. Med. Sci. 2017, 72, 450-457. [CrossRef]

4. Lv, Q.B.; Fu, X.; Jin, H.M.; Xu, H.C.; Huang, Z.Y.; Xu, H.Z.; Chi, Y.L.; Wu, A.M. The relationship between weight change and risk of hip fracture: Meta-analysis of prospective studies. Sci. Rep. 2015, 5, 16030. [CrossRef] [PubMed] 
5. Mego, M.; Mani, S.A.; Lee, B.N.; Li, C.; Evans, K.W.; Cohen, E.N.; Gao, H.; Jackson, S.A.; Giordano, A.; Hortobagyi, G.N.; et al. Expression of epithelial-mesenchymal transition-inducing transcription factors in primary breast cancer: The effect of neoadjuvant therapy. Int. J. Cancer 2012, 130, 808-816. [CrossRef] [PubMed]

6. Kaigorodova, E.V.; Tarabanovskaya, N.A.; Staheeva, M.N.; Savelieva, O.E.; Tashireva, L.A.; Denisov, E.V.; Perelmuter, V.M. Effect of minor and major surgical injury on the level of different populations of circulating tumor cells in the blood of breast cancer patients. Neoplasma 2017, 64, 437-443. [CrossRef] [PubMed]

7. Meng, S.; Tripathy, D.; Frenkel, E.P.; Shete, S.; Naftalis, E.Z.; Huth, J.F.; Beitsch, P.D.; Leitch, M.; Hoover, S.; Euhus, D.; et al. Circulating tumor cells in patients with breast cancer dormancy. Clin. Cancer Res. 2004, 10, 8152-8162. [CrossRef] [PubMed]

8. Kasimir-Bauer, S.; Hoffmann, O.; Wallwiener, D.; Kimmig, R.; Fehm, T. Expression of stem cell and epithelial-mesenchymal transition markers in primary breast cancer patients with circulating tumor cells. Breast Cancer Res. 2012, 14, R15. [CrossRef] [PubMed]

9. Ge, F.; Zhang, H.; Wang, D.D.; Li, L.; Lin, P.P. Enhanced detection and comprehensive in situ phenotypic characterization of circulating and disseminated heteroploid epithelial and glioma tumor cells. Oncotarget 2015, 6, 27049-27064. [CrossRef] [PubMed]

10. Lin, P.P.; Gires, O.; Wang, D.D.; Li, L.; Wang, H. Comprehensive in situ co-detection of aneuploid circulating endothelial and tumor cells. Sci. Rep. 2017, 7, 9789. [CrossRef] [PubMed]

11. Spizzo, G.; Fong, D.; Wurm, M.; Ensinger, C.; Obrist, P.; Hofer, C.; Mazzoleni, G.; Gastl, G.; Went, P. EpCAM expression in primary tumour tissues and metastases: An immunohistochemical analysis. J. Clin. Pathol. 2011, 64, 415-420. [CrossRef] [PubMed]

12. Ladwein, M.; Pape, U.F.; Schmidt, D.S.; Schnölzer, M.; Fiedler, S.; Langbein, L.; Franke, W.W.; Moldenhauer, G.; Zöller, M. The cell-cell adhesion molecule EpCAM interacts directly with the tight junction protein claudin-7. Exp. Cell Res. 2005, 309, 345-357. [CrossRef] [PubMed]

13. Guillemot, J.C.; Naspetti, M.; Malergue, F.; Montcourrier, P.; Galland, F.; Naquet, P. Ep-CAM transfection in thymic epithelial cell lines triggers the formation of dynamic actin-rich protrusions involved in the organization of epithelial cell layers. Histochem. Cell Biol. 2001, 116, 371-378. [CrossRef] [PubMed]

14. Maetzel, D.; Denzel, S.; Mack, B.; Canis, M.; Went, P.; Benk, M.; Kie, C.; Papior, P.; Baeuerle, P.A.; Munz, M.; et al. Nuclear signalling by tumour-associated antigen EpCAM. Nat. Cell Biol. 2009, 11, $162-171$. [CrossRef] [PubMed]

15. Osta, W.A.; Chen, Y.; Mikhitarian, K.; Mitas, M.; Salem, M.; Hannun, Y.A.; Cole, D.J.; Gillanders, W.E. EpCAM is overexpressed in breast cancer and is a potential target for breast cancer gene therapy. Cancer Res. 2004, 64, 5818-5824. [CrossRef] [PubMed]

16. Münz, M.; Kieu, C.; Mack, B.; Schmitt, B.; Zeidler, R.; Gires, O. The carcinoma-associated antigen EpCAM upregulates c-myc and induces cell proliferation. Oncogene 2004, 23, 5748-5758. [CrossRef] [PubMed]

17. Baeuerle, P.A.; Gires, O. EpCAM (CD326) finding its role in cancer. Br. J. Cancer 2007, 96, 417-423. [CrossRef] [PubMed]

18. Spizzo, G.; Went, P.; Dirnhofer, S.; Obrist, P.; Moch, H.; Baeuerle, P.A.; Mueller-Holzner, E.; Marth, C.; Gastl, G.; Zeimet, A.G. Overexpression of epithelial cell adhesion molecule (Ep-CAM) is an independent prognostic marker for reduced survival of patients with epithelial ovarian cancer. Gynecol. Oncol. 2006, 103, 483-488. [CrossRef] [PubMed]

19. Went, P.; Vasei, M.; Bubendorf, L.; Terracciano, L.; Tornillo, L.; Riede, U.; Kononen, J.; Simon, R.; Sauter, G.; Baeuerle, P.A. Frequent high-level expression of the immunotherapeutic target Ep-CAM in colon, stomach, prostate and lung cancers. Br. J. Cancer 2006, 94, 128-135. [CrossRef] [PubMed]

20. Hyun, K.A.; Koo, G.B.; Han, H.; Sohn, J.; Choi, W.; Kim, S.I.; Jung, H.I.; Kim, Y.S. Epithelial-to-mesenchymal transition leads to loss of EpCAM and different physical properties in circulating tumor cells from metastatic breast cancer. Oncotarget 2016, 7, 24677-24687. [CrossRef] [PubMed]

21. Lin, C.W.; Liao, M.Y.; Lin, W.W.; Wang, Y.P.; Lu, T.Y.; Wu, H.C. Epithelial Cell Adhesion Molecule Regulates Tumor Initiation and Tumorigenesis via Activating Reprogramming Factors and Epithelial-Mesenchymal Transition Gene Expression in Colon Cancer. J. Biol. Chem. 2012, 287, 39449-39459. [CrossRef] [PubMed]

22. Elshamy, W.M.; Duhé, R.J. Overview: Cellular plasticity, cancer stem cells and metastasis. Cancer Lett. 2013, 341, 2-8. [CrossRef] [PubMed] 
23. Mitra, A.; Mishra, L.; Li, S. EMT, CTCs and CSCs in tumor relapse and drug-resistance. Oncotarget 2015, 6, 10697-10711. [CrossRef] [PubMed]

24. Wang, K.; Kao, A.P.; Lin, T.C.; Chang, C.C.; Kuo, T.C. Promotion of epithelial-mesenchymal transition and tumor growth by 17beta-estradiol in an ER(+)/HER2(+) cell line derived from human breast epithelial stem cells. Biotechnol. Appl. Biochem. 2012, 59, 262-267. [CrossRef] [PubMed]

25. Bhat-Nakshatri, P.; Goswami, C.P.; Badve, S.; Sledge, G.W., Jr.; Nakshatri, H. Identification of FDA approved drugs targeting breast cancer stem cells along with biomarkers of sensitivity. Sci. Rep. 2013, 3, 2530. [CrossRef] [PubMed]

26. Morel, A.P.; Lievre, M.; Thomas, C.; Hinkal, G.; Ansieau, S.; Puisieux, A. Generation of breast cancer stem cells through epithelial-mesenchymal transition. PLoS ONE 2008, 3, e2888. [CrossRef] [PubMed]

27. Creighton, C.J.; Li, X.; Landis, M.; Dixon, J.M.; Neumeister, V.M.; Sjolund, A.; Rimm, D.L.; Wong, H.; Rodriguez, A.; Herschkowitz, J.I.; et al. Residual breast cancers after conventional therapy display mesenchymal as well as tumor-initiating features. Proc. Natl. Acad. Sci. USA 2009, 106, 13820-13825. [CrossRef] [PubMed]

28. Mani, S.A.; Guo, W.; Liao, M.J.; Eaton, E.N.; Ayyanan, A.; Zhou, A.Y.; Brooks, M.; Reinhard, F.; Zhang, C.C.; Shipitsin, M.; et al. The epithelial-mesenchymal transition generates cells with properties of stem cells. Cell 2008, 133, 704-715. [CrossRef] [PubMed]

29. Asiedu, M.K.; Ingle, J.N.; Behrens, M.D.; Radisky, D.C.; Knutson, K.L. TGFbeta/TNF(alpha)-mediated epithelial-mesenchymal transition generates breast cancer stem cells with a claudin-low phenotype. Cancer Res. 2011, 71, 4707-4719. [CrossRef] [PubMed]

30. Thompson, E.W.; Haviv, I. The social aspects of EMT- MET plasticity. Nat. Med. 2011, 17, 1048-1049. [CrossRef] [PubMed]

31. Shibue, T.; Weinberg, R.A. EMT, CSCs, and drug resistance: The mechanistic link and clinical implications. Nat. Rev. Clin. Oncol. 2017, 14, 611-629. [CrossRef] [PubMed]

32. Brabletz, T.; Kalluri, R.; Nieto, M.A.; Weinberg, R.A. EMT in cancer. Nat. Rev. Cancer 2018, 18, $128-134$. [CrossRef] [PubMed]

33. Ye, X.; Weinberg, R.A. Epithelial-Mesenchymal Plasticity: A Central Regulator of Cancer Progression. Trends Cell Biol. 2015, 25, 675-686. [CrossRef] [PubMed]

34. Liu, X.; Fan, D. The epithelial-mesenchymal transition and cancer stem cells: Functional and mechanistic links. Curr. Pharm. Des. 2015, 21, 1279-1291. [CrossRef] [PubMed]

35. Liu, S.; Cong, Y.; Wang, D.; Sun, Y.; Deng, L.; Liu, Y.; Martin-Trevino, R.; Shang, L.; McDermott, S.P.; Landis, M.D.; et al. Breast cancer stem cells transition between epithelial and mesenchymal states reflective of their normal counterparts. Stem. Cell Rep. 2013, 2, 78-91. [CrossRef] [PubMed]

36. Kaplan, R.N.; Riba, R.D.; Zacharoulis, S.; Bramley, A.H.; Vincent, L.; Costa, C.; MacDonald, D.D.; Jin, D.K.; Shido, K.; Kerns, S.A.; et al. VEGFR1-positive haematopoietic bone marrow progenitors initiate the pre-metastatic niche. Nature 2005, 438, 820-827. [CrossRef] [PubMed]

37. Perelmuter, V.M.; Manskikh, V.N. The Concept of a Preniche for Localization of Future Metastases. In Tumors of the Central Nervous System; Hayat, M., Ed.; Springer Science \& Business Media: Berlin/Heidelberg, Germany, 2013; Chapter 11; Volume 13, pp. 93-106. [CrossRef]

Sample Availability: Samples of the compounds are available from the authors. 